\title{
Western ethics and resource management: A glance at the history ${ }^{1}$
}

\author{
by Sandra Tomsons ${ }^{2}$
}

At the level of applied ethics, a moral philosopher assumes, as we all do, that

1. we are free.

2. we make choices and we act.

3 . we can make the right or wrong choice.

4. our actions can be morally right or wrong.

For a philosopher, specializing in the area of environmental ethics, it is a privilege and pleasure to be invited to speak to members of the Canadian Institute of Forestry. I view the invitation as a wise decision on the part of the Newfoundland Section of the CIF, because I think that ethics is very relevant to what foresters are doing. However, I am particularly pleased that foresters who know me, with whom I have been talking about sustainable forest management for several years, decided I might have something worthwhile to say to their colleagues. Since they know me all too well, I take courage in their belief that I am up to the challenge of demonstrating that it is perfectly reasonable for a moral philosopher to be standing before you.

So that you do not have to take the word of a philosopher about the importance of philosophy, I will begin with a quotation from two American forestry professors. James Coufal and Charles Spuches in a 1995 article in the Journal of Forestry, claim in the opening paragraph "We contend that it is necessary to teach values and ethics as an integral part of forestry curricula. The study of ethics should also be part of the ongoing education of all foresters." Here, I shall examine what ethics is about and the progress philosophers have made in understanding our moral obligations and moral entitlements. I will additionally try to demonstrate that Coufal and Spuches are right about the importance of philosophy to foresters.

Ethics is an area of inquiry that seeks to answer "What should I (we) do?" questions. It is about assessing human activities, and getting the assessments correct. Much of the time neither philosophers nor ordinary folk have any difficulty determining what is the right thing to do, or what is the just thing to do. We confidently answer questions like "Should I steal your laptop?", "Should I feed my two year old son?", "Should we let people die on the streets?" We do not need moral philosophers to figure out what we should do in these situations. Long before the $20^{\text {th }}$ century, philosophers in the Western philosophical tradition had discovered reasons that support the answers we confidently provide. They worked out the justifications that entitle us to have confidence in our answers.

\footnotetext{
${ }^{1}$ I am grateful to the Newfoundland organizers of the August 2000 Canadian Institute of Forester's annual meeting in Corner Brook Newfoundland for their invitation to discuss the evolution of Western ethics and the relation between our understanding of our moral responsibilities and forest management. ${ }^{2}$ Associate Professor, Philosophy, University of Winnipeg, Winnipeg, Manitoba.E-mail: stomsons@io.uwinnipeg.ca
}

For most people, certainty about what is right and wrong is not explicitly connected with the work of moral philosophers. We associate our knowledge about what is right or wrong with some authority, for example, the Church, our parents, or society's legal rules. For philosophers, such appeals to authority are inadequate, if one is claiming to have knowl-

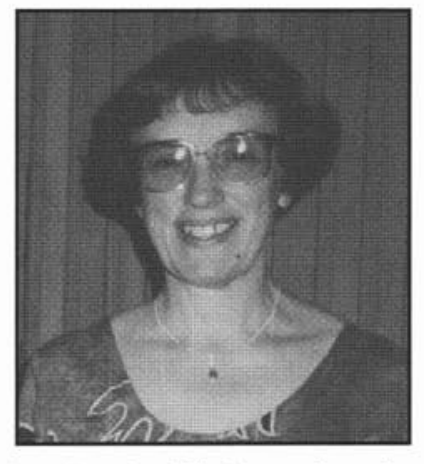
edge. The philosopher maintains that justified certainty is based upon providing an argument that conforms to laws of reasoning (logic) and contains true premises. The philosopher's contribution to ethics includes discovering the principles essential to engaging in moral reasoning, conducting the meaning analysis that ensures clarity in moral reasoning and ensuring the correctness of the logical reasoning in the arguments that are provided to justify moral judgements. In the argument in Box 2, the human rights reference in the first premise of the argument points to the moral principle that provides the basis for the moral obligation arrived at in the conclusion. The meaning analysis aspect of philosophical inquiry is illustrated in the fourth premise. Although few wives would need to construct this argument in order to arrive at the moral knowledge contained in the conclusion, there are situations in which we seek moral knowledge rather than presume to have it. In those contexts, it is necessary to carefully work through the moral reasoning. It is because the philosopher's argument provides evidence for the moral judgement we all are prepared to make, that we can claim moral knowledge and a rational basis for our certainty. Furthermore, philosophers develop moral theory (e.g., justifying the moral principle for action implied in Premise 1) and hence take thinking about ethics further than assessing types of actions (e.g., stealing, killing) or justifying particular dos and don'ts (e.g., "Sandra should be patient with her children" or "Sandra should not steal her neighbour's tomatoes.")

\section{Conclusion}

\section{A Sample Moral Argument}

It is wrong for me to beat up my husband.

1. Human beings have human rights.

2. My husband is a human being.

Therefore, 3 . My husband has human rights

4. The human right to life means human beings have a right not to be harmed.

5. Beating up a human being causes harm.

Therefore, 6. Beating up my husband violates his right to life.

Therefore, 7. It is wrong for me to beat up my husband. 


\section{Ethical judgements employed in forest manage- ment decision-making}

1. The public has the right to a say in how their forests are used.

2. Forests should be managed to sustain employment in communities.

3. There should be a timber supply for CBPP.

4. Forest harvesting should not eliminate the NF pine marten.

5. There should be protected areas representing NF's ecoregions.

Before explaining more about the activity of the moral philosopher, I want to say something about the relevance of what the moral philosopher does to what foresters do. This is rather easily done, because forest management decision-making is ultimately based upon moral judgements, and, in a sense, you already know this. Box 3 provides examples of ethical judgements that I have heard foresters agree upon in the Western Newfoundland Model Forest. The italicized words are indicators that the judgements are normative judgements. That is, in making the judgement one is making an assessment of a state of affairs rather than simply describing a state of affairs. To claim the public has decision-making rights about the province's forests and to ground these rights in some type of ownership is to make a complex moral judgement. Rights can be moral and/or legal; ${ }^{3}$ however, sustainable forest management discussion in Cana$\mathrm{da}$ (and elsewhere) has assumed that public participation is a moral right. The indicators of the normative nature of the other judgements in the box are the expressions "should" and "should not." These statements are not describing what is the case but asserting what we have a responsibility to do or make happen. The judgements about public participation, sustainable employment and steady timber supply are either explicit (1 and 2) or implicit (3) moral judgements. These judgements fall within a people-ethic. This means that they are judgements that are based to some extent on the intrinsic value (i.e., moral value) of human beings. Claiming we have a duty to protect the pine marten or establish protected areas could also be based upon a people ethic. One may justify either claim on the basis of a moral obligation to present or future generations of human beings. However, both of these claims could also be based upon the intrinsic value of non-human things (Pine Marten and

\footnotetext{
${ }^{3}$ The distinction between moral and legal rights is an important one. Those untrained in moral philosophy frequently confuse the two and the differences are significant. Whereas a moral right is discovered by moral reasoning, legal rights are created or destroyed by legally constituted bodies. Moral rights are universal, applying to all people everywhere at all times; however, legal rights apply in a particular place at a particular time. Whereas legal rights are protected by established state authorities, a moral right is only enforced if it has been recognized and made a legal right. For example, the moral right to life is recognized and protected in a legal prohibition on killing or a legal right to health care.

${ }^{4} \mathrm{Just}$ as there are competing moral theories to explain our obligations to each other, so there are competing moral theories under the umbrella of environmental ethics. At this stage in the evolution of environmental ethics, the theories are generally categorized on the basis of what gets admitted to the moral community. Any environmental ethic lets some non-human beings into the circle.
}

Moral arguments related to SFM typically require a great deal of scientific information. However, the example illustrates that empirical data itself is not enough.

1. There are 4,000 moose in Gros Morne National Park (GMNP).

2. The ecosystem in GMNP can sustain a moose population of 3,000 .

3. We should sustain the ecosystem of GMNP.

Therefore 1000 moose should be culled in GMNP.

eco-systems). They illustrate the kind of judgements that an environmental ethicist might claim are moral judgements. ${ }^{4}$

From the point of view of the forester who is making these kinds of moral judgements, what is significant is that one cannot provide evidence for these normative judgements solely by employing the content of the science courses you took on the way to becoming foresters. Normative judgements are not scientific in the sense that they are completely based upon observation or are quantifiable. If the forester is going to "make a case" for such a judgement, (for example, "We should sustain the ecosystem of Gross Morne National Park" or " 1000 moose should be culled in GMNP") it will be necessary to engage in moral reasoning. As the argument indicates, empirical data is an important component of this moral argument (Premises 1 and 2 in Box 4). So, science is an indispensable contributor of evidence in support of the conclusion. But, neither the science courses nor the economic courses taken in a Forestry Programme will deliver the normative premise (Premise 3). Therefore, science and economics cannot deliver the argument's normative conclusion. Natural and/or social scientists qua scientist cannot attempt to show that claims like "Human beings have human rights" or "Forests should be managed to sustain employment in communities" are true. Nor can they show that there is an obligation to sustain ecosystems. The scientific method, as employed by either group of scientists, cannot construct such proofs. Moreover, scientific disciplines, by themselves will not enable one to even assess the soundness of the argument. ${ }^{5}$

For more than two thousand years, the Western philosophical tradition has assumed or argued that ethical questions are questions about our moral obligations to other human beings. It has been essentially a people-ethic. What this does not mean, however, is that Western philosophers have for two thousand years viewed all members of the species as members of the moral community. Non-white men and all women had long struggles to justify their inclusion in the moral community. Philosophers' arguments contained some of the important insights that resulted in challenges to false beliefs about people excluded from the moral community. Their work contributed to the discovery of true beliefs. Consequently, philosophers' arguments have been (and continue to be) one of the forces demanding an end to unjust treatment of people of colour and women.

\footnotetext{
${ }^{5} \mathrm{~A}$ sound argument is one in which the reasoning conforms to rules of reasoning and the premises are true. If a premise is normative (and a normative conclusion requires an argument containing at least one normative premise) the scientific method cannot establish the truth value of the premise.
} 
St. Thomas Aquinas and like-minded philosophertheologians enjoyed, for centuries, an authoritative position from which they promoted a man-ought-to-rule understanding of humanity's relationship to nature.

Even at the level of moral theory, there is not much debate today among philosophers about whether we have obligations to other human beings. Philosophers may be provide different answers to the "Why?" question; but there is no significant challenge to the claim that human beings have moral value. Therefore, there is no challenge to the claim that human beings have moral obligations. There are actions that are prohibited, there are actions that are required, and there are permissible actions. One cannot assume a right to do whatever one likes, whenever one likes, to whomever or whatever one selects. Our obligations to others impose constraints upon our actions.

For almost as long as Western philosophy has been a people-ethic, the predominant philosophers in the Western tradition treated ethics as though it was inseparable from the Christian religion. St. Thomas' arguments to show that non-human animals are mere bodies and their processes machine-like contributed significantly to embedding anthropocentrism within the Western tradition (Box 5). The Church's acceptance of his views ensured that the complex beliefs making up the anthropocentric approach became embedded assumptions in the package of beliefs ordinary Christians carry around with them. The significance of Christianity's support for anthropocentrism and a people-ethic is hard to overestimate. It allowed persons, without questioning or regret, to do virtually anything they wanted to non-human nature. Unlike people, nature possessed only instrumental value. Consequently, nature, unlike people, could be owned and used for whatever served human purposes.

\section{Some philosophers who defended people-only ethics}

Aristotle (384-322 B.C)

-a rational being means higher being

St. Thomas Aquinas (1225-1274)

-there is a hierarchy of existence; man is at the high-

est level; we only have duties to man and God

Hugo Grotius (1583-1645)

-God gave humanity the right to exploit nature

Rene Descartes (1596-1650)

-animals are machines; we have no duties to them

Samuel Pufendorf (1632-1694)

-God gave dominion over the earth without imposing any restraints
${ }^{6}$ Nevertheless, Christianity, with its strong anthropocentric approach, has continued to provide an assumption-filled backdrop for the reasoning of moral philosophers. It shaped their views about the scope of human freedom (human beings are permitted to exploit anything non-human) and their views about the limits of moral responsibility (on earth, we only have obligations to other people).

\section{More philosophers who defended people-only ethics}

John Locke (1632-1704

-we only have obligations to people; but, cruelty to animals is wrong.

Immanuel Kant (1724-1804)

-we have obligations only to beings possessing autonomy and rationality, on earth, only humans qualify

\section{David Ritchie}

-1890 's a critic of Henry Salt's arguments for animal rights; explicitly argued against obligations to animals Joseph Rickaby

-Jesuit; 1890's critic of Henry Salt; argued that animals are things

For many decades now, philosophers in the Western Tradition, even those who are Christian, have not relied on God's existence and instructions in their moral reasoning. Moral theory, rather than divine revelation, provides the basis for their conclusions about what we should and should not do. ${ }^{6}$ Philosophers worked to discover the basis for moral obligation and to identify our moral obligations. Talking about membership in the moral community might be relatively recent, but the underlying concept is as old as Socrates' discussion of justice in The Republic. In a people-ethic, membership in the moral community is restricted to other persons, that is, beings who possess intrinsic value. A bearer of intrinsic value is valued for him/herself. ${ }^{7}$ If acknowledged to have intrinsic value, one has moral value and is presumed to be a member of the moral community. Being recognized as a member of the moral community is definitely better than being thought of as excluded from it, as either a black slave, a disenfranchised woman or a moose being stalked by a hunter will attest.

One's membership in the moral community imposes constraints on others. One cannot do whatever one wishes to members of the moral community. There are permissible actions, prohibited actions and even duties to act to benefit those who belong to the moral community. Until the 1970s, ethics in the Western tradition allowed only one species on the planet into the moral community. Historically (i.e., for more than 2500 years) Western ethics has been a people-ethic. What about the moral rules and even legal rules prohibiting cruelty to animals, you might ask? The moral rule was discovered (if not widely acknowledged) centuries ago. The legal prohibition exists in Canada, and it has existed for more than a century in some places in the world where the Western tradition is entrenched. It is possible that at least some of those who fought to achieve restrictions on human activities, in order to protect the interests of non-human species, believed that non-human beings possess moral value and for this reason people have moral obligations to respect them. However, for the majority in societies

\footnotetext{
${ }^{7}$ Immanuel Kant is the influential moral philosopher who distinguished between beings that exist as ends in themselves (rational persons), whose " ... very nature points them out ... a as something that must not be used merely as means . . . and non-rational beings in nature that have only a ". . . relative value as means, and are therefore called things ..." Kant (1959). Subsequently, Kant claims we have intrinsic worth.
} 
Obstacles to seeing non-human beings are in the moral community

1. God created us to rule the earth

2. We are a superior species

3. We are the stewards of the earth. (meaning, for some, we have the right to manage; for others, we have a duty to manage.)

4. Nature is only valuable, if we have tinkered.

5. Nature is things to own.

6. Human beings have the right to property. So we are entitled

- to use what we need and want

- to own the land

- to aquire, and accumulate nature

- to control and destroy nature.

7. If technology enables us to do something, then we are at liberty to do it.

8 . Whatever it is possible for us to do to nature is morally permissible.

9. Progress is good and progress is measured by humanity's ability to control nature.

implementing these regulations, the rules are thought to be justified on the basis of the animal's connection to human beings. If an action injures an animal (e.g., I kick my neighbour's dog) it is the action's consequences for human beings that are morally relevant. It is my neighbour's suffering or that injuring his dog violates his property right in the dog that have moral significance. Others, such as Immanuel Kant and John Locke argued that causing animals to suffer is morally wrong because these actions dehumanize the person who engages in them. Such desensitized human beings will not be morally virtuous and could be expected to engage in activities that cause people to suffer.

Western philosophy's people-ethic understanding of morality cannot be explained by the limited imagination of moral philosophers. It did not come about because philosophers had not thought to ask "Do only human beings have moral status?" Many philosophers asked this question and, for the most part, provided arguments to justify responding "yes." Consequently, the arguments of the philosophers gave additional support to the widespread view that we only have obligations to other human beings. Typically, the assertion that non-human beings lacked moral value was justified by arguments to show that non-human beings do not possess whatever characteristic (e.g., rationality, autonomy, freedom, ability to suffer) explains our duties to other human beings. These philosophers were steeped in the Western philosophical tradition that preceded them. In their belief packages, there were a number of major obstacles to admitting non-human beings into the moral circle. Most people schooled in the Western tradition have picked up these beliefs along the way.

All of the beliefs that are obstacles to admitting non-human beings into the moral community provide an invisible but powerful foundation for a people-only moral theory (Box 8). The beliefs are, for the most part, unexamined, and we might not be able to justify believing them to be true; nevertheless, we continue to live our lives assuming that they are true and acting as if they are true. Most interaction with the environment

\section{Pre-20th century Philosophers who challenged people-only ethics}

St Francis of Assisi (1182-1226)

- all life forms are brother and sisters, God's family

Spinoza (1632-1677)

- pantheist value in creation

John Bruckner (1726-1804)

- employed the concept "web of life"

Henry Primatt,

- a minister, in 1776, published A Dissertation on the Duty

of Mercy and Sin of Cruelty to Brute Animals

Jeremy Bentham (1748-1832)

- anything that suffers is in the moral community

Nicholos Collin

- in 1793 asked American Philosophical Association to support the protection of little-known birds on verge of extinction

\section{John Lawrence}

- clergy, published in 1796 A Philosophical Treatise on Horses \& on the Moral Duties of Man towards Brute Creation

John Stewart Mill, (1806-1873)

- laws prohibition of abuse of children should be extended to slaves and the lower animals.

Henry David Thoreau, 1859

- community of nature; denied hierarchy in nature; saw man as an inhabitant or part of nature rather than a member of society

John Muir (1838-1914)

- nature has objective value; we are one part of a whole; evil to harm nature

\section{Edward Nicolson,}

- 1879 refuted arguments to exclude non-humans from moral community; animals have powers of reason, watch your cat

\section{Henry Salt,}

- 1892 published Animals' Rights and in 1897 Cruelties of Civilization; employed the language of rights, cruelty and justice, and the notion of community (sense of kinship)

Alfred Whitehead (1861-1947)

- examined interconnectedness of all things, discussed intrinsic worth of every component of the environment.

and the economic wealth and commodity-based prosperity of Western societies rests upon our accepting some of the nine beliefs in the box as true. We find in these beliefs moral permit for economic activity that uses the land as a means to satisfy our wants and our desires.

But not all philosophers who asked whether non-human beings have moral value said no (Box 9). Some argued that humanity is not alone in possessing moral value, and we are mistak-

${ }^{8}$ For a comprehensive discussion of the evolution of environmental ethics see Richard Nash's The Rights of Nature (1989). 


\section{Early 20th century philosophers who challenged an anthropocentric ethic}

\section{J. Howard Moore}

- among first American philosophers to challenge people-only ethics

\section{Albert Schweitzer, 1915}

- reverence for life basis ethics

Royal Dixon, 1920s

- called for recognition of animals' inalienable right to life, liberty \& the pursuit of happiness (i.e., animal rights)

\section{Aldo Leopold}

-published in 1949 A Sand Country Almanac that argued

for replacing our people-ethics with a land ethic

Paul Weis, 1950

- claimed even germs have intrinsic value

en when we view non-human nature as having only instrumental value. Some of these philosophers, such as Spinoza, John Stuart Mill, and Alfred Whitehead, are respected figures in WestGern philosophy. However, their views on the moral status of nonhuman beings are not generally known, studied or accepted. ${ }^{8}$ $\dot{\Delta}$ Those who challenged the commonly accepted views that zhumanity alone has moral value and we only have moral obliorgations to other human beings did so for a variety of reasons. Essentially, they either challenged assertions about the nature .7 non-human beings that were used to justify exclusion from the moral community, or they challenged the criteria employed î 商man beings out. Thus, for example, those taking the sciencebo. that previous claims that they are machine-like or experience Drisither pleasure nor pain are simply false. Those who challenged T्तुthe normative-based approach to exclusion would argue, for example, that since it is sentience (the capacity to experience pleasure or pain), not rationality, that provides the basis of intrin๑sic value, some non-human beings cannot rationally or justly Obe excluded from the moral community.

Although many arguments for expanding our understanding of membership in the moral community to non-human species Uhave been around for hundreds of years, it is only since the ' $70 \mathrm{~s}$ that they have been before the people and the subject matter for considerable study and debate by philosophers and others. The delay is most regrettable, since humanity unknowingly and Eunintentionally has likely engaged in much morally unacFeptable activity resulting in great suffering for human and nonhuman beings. Still, it is not unreasonable that women and blacks be ushered into the moral community before cats and moose. It is unlikely that persons blind to (or unwilling to admit) the intrinsic value and moral value and of women and blacks would be able to see (or willing to admit) that non-human beings possessed such value.

\footnotetext{
${ }^{9}$ The Utilitarian and rights-based theories are the moral theories that have been the most fully developed by philosophers. Moreover, they are the theories most commonly employed in Western societies to justify both individual actions and social policy. The work of utilitarian Peter Singer (1990) and rights theorist Tom Regan (1983) best exemplifies how philosophers have expanded these moral theories to include non-humans.
}

In the '70s a small number of professional philosophers begin to challenge people-only ethics. They inquired about the value of the non-human world and duties to it at a time when "everybody's doing it." Philosophers were not leading others in this normative discussion. Scientists (ecologists and others) environmentalists, theologians, and "the people" recognized humanity was in trouble. There was agreement that we had better begin to consider our responsibility to the environment or there would be no escape from catastrophe. In the context of a crisis that thinking people could no longer avoid seeing and facing, philosophers began to ask "Why have we excluded everything non-human from the moral community?"

Philosophers raised this justificatory challenge in the direction of the central moral theories that had been developed in Western philosophy and soon made two important discoveries:

1. the Western tradition's large set of unquestioned assumptions that supported exclusion;

2. the unsatisfactory nature of many arguments used to defend the exclusion.

Discovering problems in the Western tradition's approach to and answers to moral questions related to the environment prompted a flurry of activity among philosophers who answered the questions "What are my duties?" and "Am I morally permitted to do this?" using either a utilitarian or a rights-based approach. ${ }^{9}$ Philosophers who adopted one or the other of these two moral theories now critiqued and refined their moral theory so that it could adequately address questions about human responsibility to the non-human world. As they reflected on the relationship that humanity had with the environment and worked out what that relationship should be like, they frequently uncovered arguments for excluding non-human beings from the moral community that were analogous to those that had unjustly denied entry to women and blacks. They frequently employed this similarity in their refutations of speciesism. ${ }^{10}$

It is quite likely that the well-reasoned arguments that philosophers were now constructing would have fallen on unlistening or deaf ears, if, from other directions, there were not calls to reconsider our relationship with the non-human world. Philosophers engaged in moral reasoning were joining together with

- scientists seeking to understand the interconnectedness and dependency of all beings on the planet,

- those seeking ways out of numerous environmental crises, and

- environmentalists calling everyone to walk more lightly on the planet.

The people, who could no longer pretend the status quo was fine, responded with agreement to this diverse group of experts and the door to the moral community was opened. For philosophers, the other experts, and for society as a whole, the door was not opened uniform amounts. Some philosophers and ecologists were convinced early on that the moral community includes the land, and hence we must open the door very wide. They claimed that the scope of our moral obligations is much greater than the Western tradition had ever imagined. Many found

\footnotetext{
${ }^{10}$ Speciesism is a term coined to make explicit the similarity between employing sex, race, or species membership as a basis for different treatment. We now know sexism and racism are unjust. We can also come to recognize the injustice of speciesism.
} 


\section{Find the people-ethic moral question}

$\star$ Should we reduce the moose population in Gros Morne?

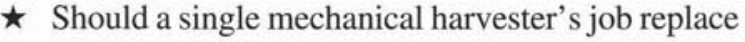
14 logger-jobs?

$\star$ Should we expend energy and money to preserve the pine marten?

$\star$ Should we clear cut in the Main River Watershed

they had to open the door to the moral community on several different occasions because of the rapid increase in understanding and new insights that were the products of moral reasoning. Sentient animals were admitted first, in particular, our pets. In the Western tradition, it was harder to recognize that the sentient animals that appear on our plates as hamburgers, spare ribs, chicken wings or lamb chops have a claim to moral value based on reasoning analogous to that which opened the door for our cats and dogs.

A smaller number of philosophers, ecologists, environmentalists, and members of society concluded that the door to the moral community must open wide enough to include all living things. Mice, rabbits, shrimp, cod, trees, flowers, black flies, viruses and butterflies are all in, and the scope of human moral responsibility has multiplied more than a hundredfold. For yet a smaller number of philosophers, ecologists and members of society, the door to the moral community was simply removed. When the land (everything admitted earlier plus mountains, rivers, soil, rocks) is recognized as providing the boundaries of human moral responsibility, we have recognized that, in some sense, there are no boundaries. Nothing is excluded from the moral community. Human beings are not morally permitted to act towards any part of nature in a manner that treats it as having only instrumental value. Humanity does not have the unqualified right to do what we wish with anything else on earth. We cannot assume that the economic activities that we have pursued in the past and are engaged in currently are morally permissible. It is reasonable to demand justification of any actions involving nature, that is, it is reasonable to request those who are using and managing ecosystems to show that their actions are morally acceptable.

Clearly, letting animals into the moral community has a huge impact on how we manage our resources. Indeed, employing either the term "manage," "our" or "resources" to refer to members of the moral community is problematic. So, we now have to reconsider our diets. Is it okay for cows, pigs, lambs and chickens to be on our plates? Should animals be the suffering subjects of medical research that benefits us? Do we have a right to make animals suffer to ensure our safety, whether the product being developed is a shampoo, oven cleanser or space ship? Is it right to destroy the habitat of other sentient beings so that we have agricultural land? More specifically for foresters: Is the habitat destruction caused by clearcutting for timber morally analogous to burning down an outport community? or, Is the economic activity that makes the pine marten extinct like ethnic cleansing?

Opening the doors to the moral community really complicates a forester's life. Nonetheless, some foresters, as a professional group, seem prepared to open the door. In 1992, the Society of American Foresters amended their Code of Ethics to express, in its Preamble and in Canon 1, their explicit commitment to Aldo Leopold's 1949 land ethic. It took the group many decades to publicly and explicitly express an ethic to which many had long been committed. Indeed, it took the express disapproval of a public that felt betrayed by the nation's foresters to move these employees of industry and government to take this stance. The Preamble's opening statement makes it crystal clear that foresters take as their first principle of action stewardship of the land and the Preamble explicitly connects the Code's Canons with respect for the land. The foresters who endorsed this addition, and it was supported by $75 \%$ of members voting, were explicitly committing their profession to rejecting people-only ethics. They were acknowledging that non-human beings are members of the moral community and that human beings are morally required to respect these members.

The CIF's Code of Ethics is an excellent example of a professional code that embodies a people- ethic. Its explicit commitments in its objectives are to forestry and the CIF. Although the mission statement employs the concept of stewardship, it is expressed as "the stewardship of Canada's forest resources." The expression "forest resources" is clearly more consistent with ascribing instrumental value than intrinsic value to forest ecosystems. "Forest resources" brings to mind the economic value and uses of a forest not what it is in and of itself. If they understand their commitment to the forest in terms of the value of forest resources, that is, the instrumental value of forest ecosystems, then Canadian foresters at best ignore and at worst deny the intrinsic or moral value of forests. ${ }^{11}$

The forester's decision-making moral responsibilities are extensive even if only a people ethic needs to be employed. Ensuring just treatment of all with an interest in and an entitlement to a voice in management decisions is often a daunting task. However, if it is necessary to work from an environmental ethic, not only do the moral responsibilities increase but so does the complexity of the moral reasoning required to arrive at decisions. From a people-ethics perspective, the only straightforward moral question in Box 11 is the job question. Jobs make livelihoods possible and livelihoods are associated with the human right to life. It is clear then, that moral reasoning, not scientific data alone, is necessary to discover the answer this question. From a people-ethic perspective the other three questions in the box are simply prudential. They are questions about how we make the best use (from the perspective of human beings) of

\footnotetext{
${ }^{11}$ Following my presentation, Chris Lee and others informed me that the CIF has been working on revisions to the Code of Ethics. I have had the opportunity to see the proposed changes. While it contains important revisions, the Code of Ethics does not yet express the commitment of Canada's foresters to a land ethic. Forest ecosystems are still forest resources. The implications of recognizing a stewardship of forest resources and recognizing a stewardship of forest ecosystems are very different. The former is a commitment to sustainable development (i.e., maintaining forests for economic activity) and the latter is a commitment to restricting economic activity for the good of forest ecosystems. The current draft of the revisions in its explanation of forest stewardship explicitly commits to '... maintain, protect and enhance the integrity, utility and value of the forest resource for the benefit of society, without compromising the opportunity for present and future generations to meet their objectives." Unlike the membership of the SAF (or for that matter, the Vision statement of The Canada Accord) the CIF appears to be unwilling to accept a land ethic. Hopefully, if the current proposed revisions are the ones Canadian foresters are eventually asked to accept or reject, discussion will ensure that foresters understand acceptance means an ongoing commitment to a people-only ethic.
} 
available natural resources. Forest ecosystems are natural commodities. Since nature is not in the moral community, we cannot wrong nature. Our decision about the moose in the Park, pine marten or Main River are ultimately only decisions about what people want, and treating people fairly.

Foresters today frequently turn to a forester turned moral philosopher to explain their understanding of the moral community. By 1949, American forester Aldo Leopold had worked out a holistic environmental ethic that he called a land ethic. He explicitly employed the concept of community and knew that he was arguing that the door to the moral community should be as wide open as it can be. Leopold's moral reasoning, that he based on ecological theory and moral theory, lead him to conclude that the moral principle that humanity must employ in decision-making is as follows: A good action preserves the integrity, stability and beauty of the biotic community; a bad action violates the integrity, stability and beauty of the biotic community. Human beings are primarily obliged to act in the interests of ecosystems. We are obligated to step down from whatever lofty pedestal we have fashioned for ourselves and understand our living in terms of our membership in the ecosystem community. Leopold thought that moral philosophers in Western philosophy correctly understand that moral relationships and obligations arise in the context of community. They have just been operating with a mistaken notion of community. Communities are not arbitrarily defined and constructed human groupings. A community is an ecosystem and it is the good of the ecosystem that is the primary responsibility of moral agents.

Although the CIF's Code of Ethics does not in its current form or proposed revisions follow the Society of American Foresters in calling upon its membership to obey Leopold's moral principle, the Newfoundland Section of the CIF, does seem to implicitly accept Leopold's land ethic. The Registered Forester Program for Newfoundland and Labrador, approved by the Minister of Forest Resources and Agrifoods in June 1996, claims in its first objective that the "ultimate goal" of the practice of forestry is maintaining the long-term health of Newfoundland's forest ecosystems. Likely, neither the NF Section of CIF nor the Minister of Forest Resources and Agrifoods would describe the program's purpose in terms of an environmental ethic. Nevertheless, because the goal has not been couched in terms of an explicit people-ethic and because it does not reduce forest ecosystems to forest resources, the program is much more consistent with a land ethic than the CIF Code, and thus it acknowledges a more comprehensive set of obligations.

I claimed at the outset that Coufal and Spuches were wise when they told foresters in 1995 to study ethics. I have attempted here to justify this praise by showing the extent to which forest management decision-making presupposes ethical judgements. You foresters make some pretty significant moral assumptions in your line of work. You assume:

- the human species is more important than any other;

- the human right to control the planet; and

- morality approves human consumption that exceeds needs.
Therefore, you must have decided to accept (or, more likely, assumed to be true) a people-only ethic. You must be assuming the truthfulness of some answer to the question: "Who is in and out of the moral community?" How otherwise can you assume, for example, the following:

- forest ecosystems ought (or ought not) to be primarily managed for timber;

- endangered species should (or should not) be protected; and

- there should (or should not) be protected areas.

Behind all of your forest management decisions there are normative judgements and behind the moral judgements there is a moral theory. You can adopt the judgements and the theory rationally, or you can carry around a very large set of unjustified beliefs that you continue to employ on a daily basis.

Presumably, foresters reject the notion of basing sustainable forest management decisions on bad science. Should you base the most important decisions you make and the actions you take every day on a set of unjustified moral judgements and an unjustified moral theory? Forester training and forester decisionmaking practice allow foresters to be blind to the need to engage in moral reasoning in order to do what you do well. However, if one has discovered the significant role of moral reasoning in forest management and one still avoids moral reasoning, one's omission is morally wrong. Some omissions, like not feeding one's children, are serious moral wrongs. Given the significance of the consequences of most forest management decisionmaking, the moral wrong when the moral reasoning component of sustainable forest management is omitted is a serious one.

I think Coufal and Spuches are right. You do need a heavy dose of moral theory and training in moral reasoning to do well what you do. Moreover, you need to engage in the kind of moral reasoning that allows you to select the moral beliefs and the moral theory you are carrying around with you. You should know what it is, and the public that suffers or benefits from the normative decisions you make is definitely entitled to know what it is.

\section{References}

J.E. Coufal and C.M. Spuches. 1995. Ethics in the Fore. Journal of Forestry September: 30-34.

A. Leopold. 1949. A Sand County Almanac. Oxford University Press, Madison; Oxford.

R. Nash. 1989. The Rights of Nature: A History of Environmental Ethics.: The University of Wisconsin Press, Madison.

Plato. Republic. translated by F.M. Cornford, Oxford University Press, 1967.

T. Regan. 1983. The Case for Animal Rights. University of California, Berkeley.

P. Singer. 1990. Animal Liberation, $2^{\text {nd }}$ edition. New York Review of Books, New York. 